\title{
Reported Sleep on Maintenance Haemodialysis
}

\author{
ROBERT J. DALY,* M.B., D.P.M. ; CHRISTINE HASSALL, $†$ M.SC.
}

\begin{abstract}
Ummary: Subjective estimates of sleep in patients undergoing maintenance baemodialysis at home showed significant differences between dialysis nights and other nights; both patients and spouses lost sleep on dialysis nights. The sleep debt thus accumulated was not so well repaid in spouses as in patients. No pronounced differences were found between sleep on various forms of maintenance haemodialysis, and sleep did not show a consistent change over the three days between dialyses. The findings are interpreted as indicating the importance of functional rather than physical causes of insomnia in dialysis patients.
\end{abstract}

\section{Introduction}

The relation between sleeping, waking, and uraemia has long been of interest, and Schreiner (1959) described the uraemic patient's drowsiness by day with insomnia at night and the atypical response to sedatives. Gonzales et al. (1963) reported insomnia in his patients being treated with haemodialysis, thought to be of functional origin. Shea et al. (1965), however, noted that "soporific effects of dialysis occurred in every patient unless the patient was particularly anxious," a view supported by Menzies and Stewart (1968). An objective study of sleep and dialysis was made by Passouant et al. (1967). Using E.E.G. recordings, they found, before dialysis, that the total duration of sleep was diminished, with myoclonic jerks and periods of wakefulness occurring throughout the night. Paradoxical (R.E.M.) sleep was diminished and occurred at irregular intervals. After dialysis the sleep cycles became regular.

In the light of these discrepancies it seemed of value to ask patients to record their sleep while undergoing maintenance haemodialysis at home and in hospital.

\section{Subjects and Method}

This study reports data collected from 19 hospital dialysis patients at the medical renal unit of the Royal Infirmary of Edinburgh and 15 home dialysis patients and their spouses being treated from the Birmingham Centre for Chronic Dialysis, East Birmingham Hospital. The Edinburgh patients were dialysed twice weekly for about 12 hours, whereas the Birmingham patients were dialysed three times weekly for about 10 hours. All of the home dialysis patients in Birmingham were dialysed at night, whereas 10 of the Edinburgh patients were dialysed in the day and nine at night. All but four of the Edinburgh patients were prescribed hypnotics (butobarbitone, nitrazepam, or Tuinal). Only four Birmingham patients and one spouse used hypnotics. Patients recorded their sleep on charts similar to those used by Tune (1968), with half-hour columns through which the patient drew a line to represent time judged to have been spent sleeping. The recordings were limited to two consecutive weeks because heavy research demands are made on these pioneering but easily fatigued subjects. Time spent sleeping at night and in each 24 -hour period was noted.

* Lecturer, Department of Psychiatry, University of Edinburgh, Edinburgh EH10 $5 \mathrm{HF}$.

† Senior Research Associate, Department of Psychiatry, Queen Elizabeth Hospital, Birmingham 15 .

\section{Results}

Time and Location of Dialysis.-Patients maintained on night dialysis were thought by staff to be better adjusted medically and socially. In fact, though they had a slightly greater mean total weekly sleep (night, $62 \pm 10.6$ hours; day, $55 \pm 12$ hours), this difference was not significant $(t=1 \cdot 15$, D.F. $=18)$. The hospital patients dialysed at night reported slightly more sleep per week $(62 \pm 10 \cdot 6$ hours) than home patients ( $59.6 \pm 8$ hours), but again the difference was not significant $(t=0.61$, D.F. $=23)$.

Home Dialysis Patients v. Spouses.-Home dialysis patients on average slept more than their spouses each day of the week, but significant differences between the groups occurred only on non-dialysis nights (see Chart). The patients' mean sleep on dialysis nights was 7.41 hours while on other nights the mean was 9.43 hours $(P>0.01)$. By contrast Tune (1969) reported normal subjects as obtaining a mean sleep of 7.37 hours. On dialysis nights both patients and spouses got significantly less sleep than on other nights. The mean weekly totals were greater for the patients, who slept $59 \cdot 6( \pm 8)$ hours, while spouses slept $53.6( \pm 5.5)$ hours $(t=2.39, P>0.05)$.

Time from Last Treatment.-Though the patients slept significantly more the night after dialysis than the night before (correlated $t=1.99$, D.F. $=18, P>0.05$ ), these differences were eliminated if all sleep, 24 hours before and after dialysis, was compared $(t=1 \cdot 1$, D.F. $=18)$. To investigate the relative sleep during the three 24 -hour periods following dialysis, when three days intervened between dialyses, Friedman's two-way analysis of variance by ranks (Siegel, 1956) was performed. This yielded a $\chi_{\mathrm{r}}{ }^{2}$ of 0.61 (D.F.=2), which was not significant-that is, on maintenance dialysis sleep appears to bear no pronounced, consistent relationship to time from treatment.

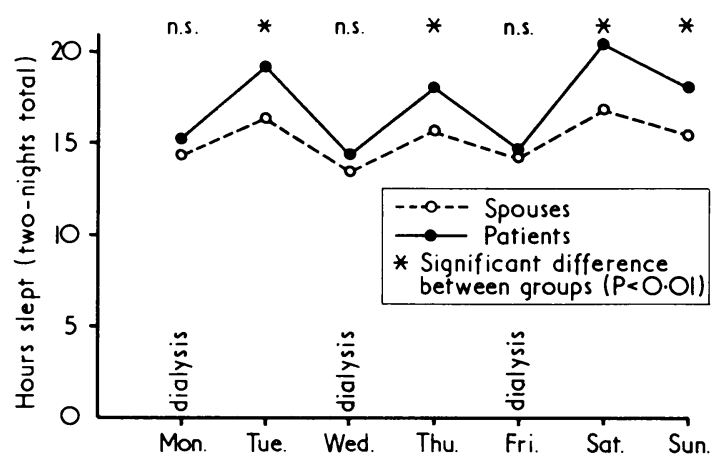

Reported sleep of 15 home dialysis patients and spouses.

\section{Discussion}

Too frequently anecdotal evidence is advanced to support the claims of protagonists of various forms of administering maintenance haemodialysis. It would seem reasonable to consider reported sleep as one criterion of effectiveness, or patient acceptance, of treatment. From this study it would seem that subjective estimates of sleep do not show dif- 
ferences between patients treated at home or in hospital, by day or at night. Furthermore, the accumulation of metabolites between dialyses has no apparent effect on this measure.

The findings concerning home dialysis are of particular importance, since the spouse provides one form of control. It is seen that on dialysis nights both patients and spouses lose sleep, but the patients regain their "sleep debt" more than their spouses on non-treatment nights. This suggests a psychological rather than a metabolic cause of insomnia on dialysis. It would add to the evidence showing stress on families of patients being treated with dialysis, particularly where the treatment is conducted in the home. This stress on the spouse would seem understandable in terms of their feelings about the patient's illness, and having responsibility for operating a complex life-support system. But, obviously, other criteria must be considered in deciding on the location for treatment-for example, the additional time the home dialysis patient spends with his family.

Regarding the reliability of these data, Lewis (1969) investigated the accuracy of subjective estimates of sleep with objective (E.E.G.) recordings. He showed that, though subjects are not accurate in their estimates of the quantity of sleep, their estimates do shift in the direction of the objective measures. Thus they are reliable indices of change of sleep. Furthermore, in this study the data from patients in two geographically separate treatment centres showed no significant differences whereas there were significant differences between spouses and patients.

We wish to thank the Directors of the Dialysis Units, Dr. J. S. Robson in Edinburgh and Dr. B. H. Robinson in Birmingham, for permission to study patients under their care. We also acknowledge the criticism and advice of Drs. S. A. Lewis and D. H. Morgan, of the departments of psychiatry at the Universities of Edinburgh and Birmingham respectively.

The study was supported in part by S.H.E.R.T. Grant.

Gonzalez, F. M., Pabico, R. Feferences Schreiner, G. E. (1963). Transactions. American Society for Artificial
Internal Organs, 9, 11.

Lewis, S. A. (1969). British fournal of Psychology, 60, 203.

Menzies, I. C., and Stewart, W. K. (1968). British Medical fournal, 1, 544. Passouant, P., Cadilhac, J., Baldy-Moulinier, M., and Mion, C. (1967). Revue Neurologique, 117, 525.

Schreiner. G. E. (1959). Medical Annals of the District of Columbia, 28, 316 .

Siegel, S. Non-parametric Statistics for the Behavioural Sciences, New York, McGraw-Hill, 1956.

Shea, E. J., Bogdan, D. F., Freeman, R. B., and Schreiner, G. E. (1965). Annals of Internal Medicine, 62, 558 .

Tune, G. S. (1968). Ergonomics, 11, 183.

Tune, G. S. (1969). British fournal of Industrial Medicine, 26, 54.

\title{
Sleep Habits and Symptoms in Male Medical and Surgical Patients
}

\author{
M. W. JOHNS,* M.B., B.S., B.SC. ; P. EGAN, † ; T. J. A. GAY, $\ddagger$ B.MED.SC. ; J. P. MASTERTON, $\$ M.B., DIP.OBST., F.R.C.S.
}

British Medical fournal, 1970, 2, 509-512

\begin{abstract}
ummary: A questionary survey of symptoms and $\checkmark$ sleep habits at home among 100 adult male medical and surgical patients showed that the duration of sleep at night was similar to that reported for the general population, decreasing with age from 20 to 50 years and increasing again after 60 years. The duration of daytime sleep increased with age. The degree of sleep disturbance in different patients was compared in terms of the total duration of sleep and the time spent lying awake in bed at night. Increasing age, ischaemic heart disease, and neurotic illness were the main factors associated with long-term disturbances.
\end{abstract}

\section{Introduction}

One of the oldest and most widely used therapeutic manœuvres in medicine is to put the patient to bed, to rest, and, in particular, to sleep. Disturbances to sleep are known to be common among psychiatric patients, particularly in those suffering from anxiety and depression (McGhie, 1966; Hawkins and Mendels, 1968), but surprisingly little is known about the sleep habits of patients in different age groups who have physical symptoms. Rudolf (1955) studied the sleep of small groups of patients treated by physicians at home and in hospital, using daily records of the hours of sleep. $\mathrm{He}$ suggested that patients with cardiovascular disease slept less than those with gastrointestinal, genitourinary, or respiratory disease. The few patients investigated and the absence of a detailed description of symptoms made this conclusion only tentative. Weiss et al. (1962) found that chronic sleep disturbances, as reported in a sleep questionary, increased with age in groups of psychiatric patients, medical patients, and

*Research Fellow.

†Medical Student.

$\ddagger$ Research Student.

\&Research Student.
SAssociate Professor of Surgery.

Department of Surgery, Monash University, Melbourne, Australia. healthy airforce personnel. The psychiatric patients had significantly more sleep disturbance than the medical patients, who did not differ significantly from the healthy controls. Neither the symptoms nor the diagnoses of these patients were described.

A sleep questionary was used to describe a pattern of increasingly disturbed sleep with age in healthy adults in Scotland (McGhie and Russell, 1962), and Monroe (1967) showed that different subjective responses to such a sleep questionary by "good" and "poor" sleepers reflect objective differences in sleep measurements. Lewis (1969) suggested that individual subjective reports about a night's sleep tend to underestimate the total sleep time and overestimate the delay to sleep onset as measured by electroencephalographic methods in a sleep laboratory. Nevertheless, the overall correlation between subjective and objective reports of sleep measurements in Lewis's study was significant and justified the use of subjective reports to compare sleep habits in groups of people.

We have designed a questionary to study the usual pattern of sleep in male patients admitted to the general medical and surgical wards of a large teaching hospital in Melbourne. This paper deals with changes with age in the sleep habits of such patients when they are at home as well as the relation between their sleep disturbances and physical and psychological symptoms.

\section{Methods}

Questionaries.-The sleep questionary consisted of 28 questions relating to most subjective aspects of an average night's sleep. A range of possible answers was provided from which the patients selected the most appropriate. Detailed information about physical illness and symptoms as well as a rating for neurotic illness was provided by the male version of the Cornell Medical Index (C.M.I.) Health Questionnaire (Brodman et al., 1949; Culpan et al., 1960). This is a self- 